\title{
A Study on the Application and Residues of Plant Growth Regulators in the Fruit Sugarcane Grown in the Sub-Suitable Region
}

\author{
Jiaju Lu (Corresponding author), Chaoyun Lei \& Lansong Zha \\ Guizhou institute of subtropical crops, Xingyi 562400, Guizhou, China \\ Tel: 86-859-391-1753Ｅ-mail: lujiaju@126.com \\ Xiaolang Li \\ Guizhou institute of sci\&technical Information, GuiYang 550004, China \\ Jing Fang \\ QianXiNan national vocational technical college, XingYi 562400, China \\ Wei Zhuang \\ Guangzhou Automobile College, GuangZhou 510800, China
}

The research is financed by three projects: Qian Nong Ke He (importance) 08035; Qian Ke He “J” [2008] 2077 and Qian Nong Ke He (talents) 023.

\begin{abstract}
In this paper, we used plant growth regulators, such as gibberellin and ethephon to treat fruit sugarcane Qiantang 5 respectively. The results show that the spraying of gibberellin on the plants with its concentration of $30 \mathrm{~g} /$ year. $667 \mathrm{~m}^{2}$ has positive effects on most agronomic characters, such as growth speed, plant height, valid stalks, brix, sucrose content and yield. The residue of gibberellin is $0.05 \mathrm{mg} / \mathrm{kg}$. However, ethephon has no positive effects on agronomic characters except the growth speed.
\end{abstract}

Keywords: Gibberellin, Ethephon, Yeild, Residue

\section{Introduction}

Recently research results showed that application of plant growth regulator in sugarcane production, $\mathrm{GA}_{3}$ has significantly positive effects on the height, valid stalks and yield of the fruit sugarcane (Li et al., 1992; Tan et al., 2007). However, there is no report about the application of plant growth regulators in fruit sugarcanes in the sub-suitable regions. With the rapidly increase of living level, the consumption of safe food is becoming a general trend. During the period of 2008-2009, to identify on the residues of plant growth regulator in the fruit sugarcane, a study on the application and residue of plant growth regulators has been done in the fruit sugarcane grown at a sub-suitable region, Wanfenglin of Xingyi City in Guizhou province, China.

\section{Samples and Methods}

\subsection{Samples}

The type of fruit sugarcane used in the experiment is QianTang 5 cultivated by Guizhou Institute of Subtropical Crops, China. The plant growth regulators, gibberellin and ethephon, come from the 18th pharmaceutical factory of Shanghai Tongren Pharmaceutical Company Limited and the Qingdao Hundred Standing Grains Sources Bio-Engineering Limited Company respectively.

\subsection{Methods}

\subsubsection{Field management}

In its seeding stage, the sugarcane should be applied with carbamide $\left(15 \mathrm{~kg} / 667 \mathrm{~m}^{2}\right)$ to the field, irrigated with enough water to dissolute the fertilizer, and weeded by manual or chemical methods. In its growth stage, the sugarcane should be applied with $15 \mathrm{~kg}$ carbamide and $50 \mathrm{~kg}$ of NPK complex fertilizer per $667 \mathrm{~m}^{2}$. After the fertilization, the sugarcane should be covered with soil and weeded again. When the sheaths of the sugarcane are 
becoming separated form its stem, they should be peeled off. The items in the field investigation include the growth speed, plant height, stem diameter, valid stalks, brix, sugar content and yield of the sugarcane. The disease observation on the sugarcane is made once a week during a span from the early July to the early November, monitoring its disease situation for immediate treatment. The sampled test of remaining Gibberellin and Ethephon in the sugarcanes is conducted by the time when the sugarcane becomes mature.

\subsubsection{Experimental Design}

The experiment following the randomized blocks design is done in 3 replications, each of them occupies $12 \mathrm{~m}^{2}$ with $40 \mathrm{~cm}$ in width, $35 \mathrm{~cm}$ in depth and 30m in length. In terms of Liu and Jiang (2002), 4 kinds of treatment with gibberellin, coded as A, B, C and CK, are accorded to the sugarcanes planted at the region of Wangfenglin in Xingyi City. The spraying days are timed on April 4, July 9, Aug. 13, Sep. 13 and Oct. 31. The concentration rate in each spraying is $1: 1: 2: 4: 4$, and the total dosages for each treatment are: $\mathrm{A}=30 \mathrm{~g} / 667 \mathrm{~m}^{2}$ year, $\mathrm{B}=15 \mathrm{~g} / 667$ $\mathrm{m}^{2}$ year, $\mathrm{C}=7.5 \mathrm{~g} / 667 \mathrm{~m}^{2}$ year and $\mathrm{CK}=0 \mathrm{~g} / 667 \mathrm{~m}^{2}$ year. Similarly, according to $\mathrm{Li}$ et al (2007), 4 kinds of treatment with ethephon, coded as A, B, C and CK, are accorded to the same sugarcanes planted at the same region, but on different days, with different concentration and different dosage. In the treatment with ethephon, the spraying is dated on June 4 and Oct. 31, the concentration rate in each spraying is $1: 4$, and the total dosages for each treatment are: $\mathrm{A}=21 \mathrm{~g} / 667 \mathrm{~m}^{2}$ year, $\mathrm{B}=16 \mathrm{~g} / 667 \mathrm{~m}^{2}$ year, $\mathrm{C}=10 \mathrm{~g} / 667 \mathrm{~m}^{2}$ year and $\mathrm{CK}=0 \mathrm{~g} / 667 \mathrm{~m}^{2}$ year. The sampling is done 65 days later after the last spraying of the regulators.

\subsubsection{Detection of Residue}

The residues of gibberellin and ethephon remained in the harvested sugarcanes are detected by the Center for the Fine Chemicals in Guizhou University. The residue of gibberellin tested in light of SN 0350-95, in which the gibberellin in the sample is extracted with acetone and ethyl acetate, and after anti-extraction, removal of interfering substances and fluorescence spectrophotometry, is more than $0.03 \mathrm{mg} / \mathrm{kg}$. The residue of ethephon tested in light of NY/T 1016-2006, the gas chromatography method to ethephon residues in fruits and vegetables, is more than $0.01 \mathrm{mg} / \mathrm{kg}$.

\section{Results and Analysis}

The data observed are input into SAS 9.1 to do the analysis, and then the results are displayed as follows.

$<$ Table 1>

The table 1 shows ethephon increases the growth rate of the sugarcane between July and Sep with treatment A, but it has no obvious effects on plant height, stem diameter, valid stalks, brix, sugar content and yield of the sugarcane. Moreover, its residue detected can not be detected within the limit of $0.01 \mathrm{mg} / \mathrm{kg}$. The researcher infers the differences of the annual average temperature and effective accumulated temperature between Guizhou and Guangxi may explain the varied result from the study by Li et al (2007) in Guangxi Province where the temperatures are higher than Guizhou Province. To some extent the higher temperature is the quicker the growth rate of the sugarcane would be, because the fruit sugarcane belongs to tropical and subtropical crops and the treatment with high concentrated ethephon in the late period of the sugarcane has the effect of ripeness promotion and sugar improvement(Li. Y.R., 2004).

On the contrary, Gibberellin with treatment A has significant or highly significant effects on the improvement of agronomic and economic traits of the sugarcane, which conforms basically to the research by Liu and Jiang (2002). However, the residue is highest among all kinds of the treatment, reaching up the level of $0.05 \mathrm{mg} / \mathrm{kg}$. In addition, comparing with the treatment of A, B and C, the stem diameter of the sugarcane treated with $\mathrm{CK}$ is much bigger, which could be explained as that the high concentrated gibberellin promote the lengthening in the parts of internodes of the sugarcane, making it appeared to be in the shape of cylinder. Lacking the growth regular the sugarcane treated with CK grows slower, and the internodes of the sugarcane are closer together and displayed in the shape of olive. So the stem diameter of the sugarcanes treated with CK is bigger than that of those treated with A, B, and C.

\section{Conclusion}

The study indicates it can significantly improve the growth speed, plant height, stem diameter, valid stalks, brix, sugar content and yield of the sugarcane at the sub-suitable region in Guizhou Province when the spraying of $30 \mathrm{~g} / 667 \mathrm{~m}^{2}$ per year on the fruit sugarcane and the last spraying timed on the 65 days earlier before its harvest. What is more, the gibberellin residue detected in the sugarcane is only $0.05 \mathrm{mg} / \mathrm{kg}$, which is for less than the counterpart of the American regulation on oranges and sugarcanes that is $0.15 \mathrm{mg} / \mathrm{kg}$ (Xu. A. D., 2009), although China has not enacted corresponding rules on that. The study also shows that ethephon is not suitable to be taken as a growth regulator of the fruit sugarcane. We are not clear if it is the temperature or the concentration of the 
ethephon or the both that causes such a result, and why its residue can not be detected. Those questions are expected to be answered by further studies.

\section{Acknowledgment}

The authors are grateful to Zhou Zhengbang, Lu Ping and Liu Fanzhi for their valuable assistance and technical support.

\section{References}

Li, Y.R., Lin, Y.K., Yang, L.T., Ye, Y.P., Pan, H., Chen, Z.C., Wei, Z.T \& Qin, B.Q. (1992). Effects of sucrose-cane promote on yield and sucrose content in sugarcane. Journal of Guangxi Agricultural University. 11(3):31-36.

Liu, W.C \& Jiang, H. (2002).Technologies for high-yielding sugarcane cultivation of in Yuqing county. Journal of Guizhou Agricultural Sciences. 30(3):62.

Li, Y.R., Yang, L.T., Ye, Y.P., Yao, R.L., Wang, A.Q \& Lin, Y.K. (2007). Mechanism of ethephon on increasing cane yield and sucrose \% cane in Sugarcane. Southwest China Journal of Agricultural Sciences, 20(1):151-156.

Li, Y.R. (2004). Beneficial effects of ethephon application on sugarcane under sub-trepical climate of China. Journal of Sugar Tech, 6(4):235-240.

NY/T 1016-2006. Agricultural industry standards of People's Republic of China [S].

SN 0350-95. Detect methods of $\mathrm{GA}_{3}$ residues in export fruits. Chinese Import and Export Commodity Inspection Bureau [S].

Tan, X.P., Li, N.M., Zhou, Y.M., Zhang, J., Wang, Y., \& Chen, Z. (2007). The effects of different concentration of gibberellin on the quality and yield of garden cane. Journal of Suagar and Canesugar, 4, 8-13,27.

Xu, A.D. (2009). Research Advance in the Toxicity and Residue of Plant Growth Regulator in Vegetables in China. Journal of China Vegtables, 8(3): 61-66.

Table 1. The Effects of Application and Residues of Plant Growth Regulators in the Sugarcane

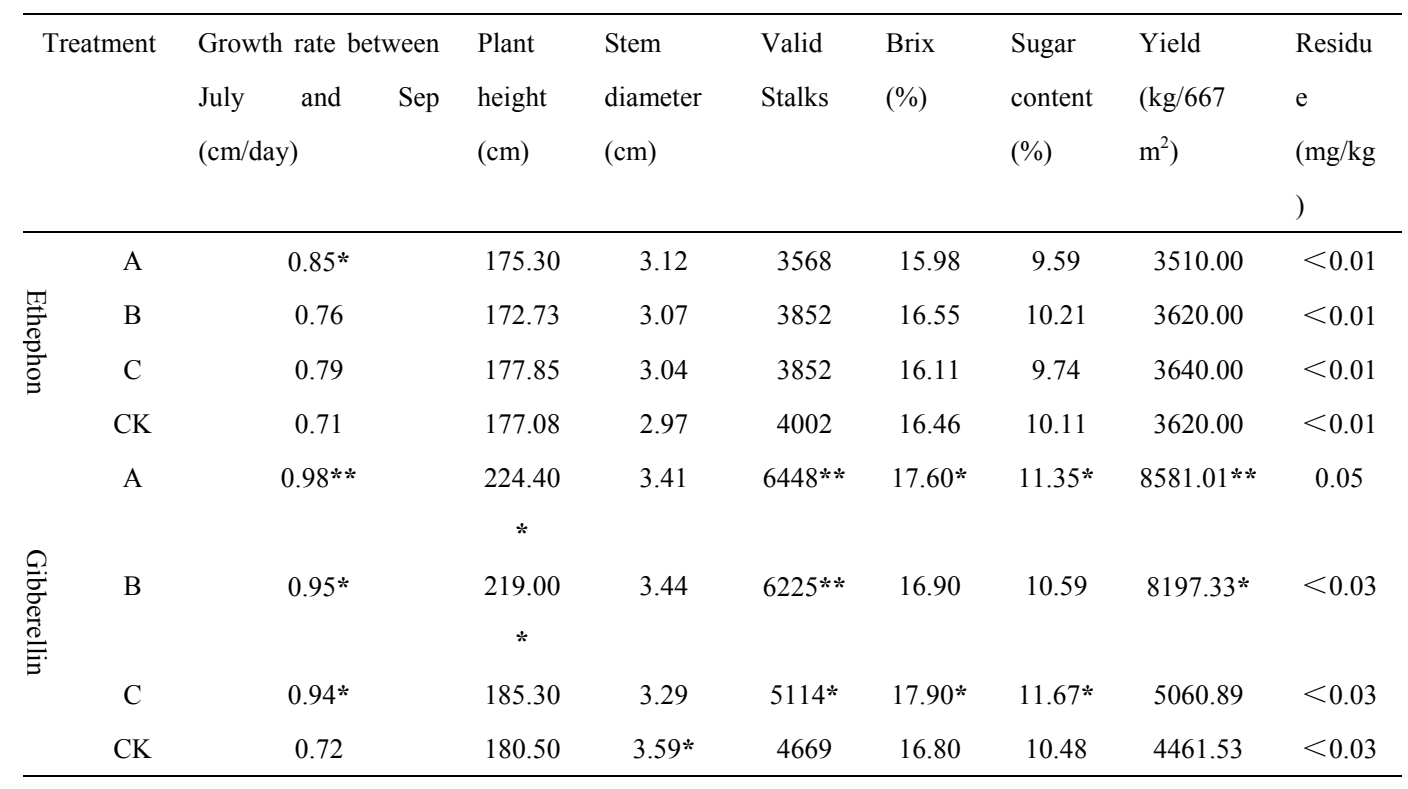

Notes: $*=$ Significant at $5 \%$ level; $\quad * *=$ Significant at $1 \%$ level. 